\title{
Wisdom of group forecasts: Does role-playing play a role?
}

\author{
Dilek Önkal $^{\mathrm{a}, *}$, K. Zeynep Sayım ${ }^{\mathrm{a}}$, Michael Lawrence ${ }^{\mathrm{b}}$ \\ a Faculty of Business Administration, Bilkent University, Ankara 06800, Turkey \\ ${ }^{\mathrm{b}}$ Australian School of Business, University of New South Wales, Sydney 2052, Australia
}

\section{A R T I C L E I N F O}

Available online 4 October 2011

Keywords:

Consensus

Forecasting

Group decisions

Judgement

Role playing

\begin{abstract}
A B S T R A C T
Forecasting plays a special role in supply chain management with sales forecasts representing one of the key drivers for collaborative planning and decision making in the organisations involved. We review the important role played by judgemental forecasts in this area, focusing on group predictions. Noting the scarcity of research using group forecasts, we present the results of an experiment where consensus forecasts are elicited from structured groups with and without role-playing. Comparisons with groups without any assigned roles show that getting into tailored organisational roles does have a significant effect in the resultant forecasts. In particular, members of the role-playing groups show less agreement with consensus forecasts and display a strong commitment to their assumed roles and scripts. Furthermore, role-playing groups leave a higher percentage of model-based forecasts unadjusted and when they do make an adjustment, it is significantly less than the groups, whose members are not assigned roles. Differences between the role-playing conditions are interpreted as highlighting the importance of role framing on forecast adjustment and group forecasting behaviour. Future research directions are proposed to improve the accuracy and acceptance of group forecasts.
\end{abstract}

(c) 2011 Elsevier Ltd. All rights reserved.

\section{Introduction}

Forecasting accuracy represents one of the most critical elements affecting efficiency and cost structures in supply chain systems [1-6]. The direct influence of sales forecasts on operational decision processes and business planning has been instrumental in instigating work on forecast improvements, as is the focus of this special issue. While forecasting has been the topic of much research over the last 40 years, the majority of the work has been algorithmic in nature with the influence of the human dimension receiving relatively recent attention. Studies attesting to the wide use and value of 'judgemental' forecasts (and judgemental adjustments to model-driven forecasts) in supply chain planning have highlighted the importance of individual and contextual factors affecting predictive accuracy [7-11]. Most of this research has focused on the individual forecaster and has typically involved experimental settings where participants are given a cover story asking them to predict sales given time series information on previous values (see Ref. [12] for a detailed review). While some forecasting support may be provided via model-based forecasts, no particular role information and guidance is given to participants. These studies have explored such issues as the judgemental forecasters' response to

\footnotetext{
* Corresponding author. Tel.: +90 3122901510; fax: +90 3122664960.

E-mail addresses: onkal@bilkent.edu.tr, dilekon@gmail.com (D. Önkal), kzeynep@bilkent.edu.tr (K. Zeynep Sayım),

Michael.Lawrence@unsw.edu.au (M. Lawrence).
}

time series characteristics, planned promotions or other external shocks not reflected in the historical series, and their response to varying validity of the supplied forecasts. A consistent finding has been the prevailing tendency to make more adjustments than necessary, reflecting an unwarranted disregard for the model-based forecasts $[9,13]$.

As useful as the vast body of findings from this research activity have been, the experimental setting bears little resemblance to that pertaining in organisational contexts. In their detailed field work on forecasts in supply chain systems, Fildes et al. [9] describe the typical organisational forecasting setting as comprising a committee generally made up of representatives of marketing, sales, production, and the forecasting unit, which is responsible for providing the base line forecast and for guiding the committee in understanding its use. Typically these roles can be seen as competing with the marketing representatives pushing for higher forecasts, production managers asking for lower forecasts, and forecasting representatives seeking accurate forecasts. In particular, Lawrence et al. [14] show that while the stated organisational goal may be developing the most accurate forecast, different members of a forecasting committee often have competing incentives, which tend to bias the forecasts. Hence, the individual expectations from the forecasts may vary, which in turn may affect forecast accuracy and use [15], thus leading to different organisational costs [16]. Furthermore, the effects of group forecasting processes become imperative, and yet, surprisingly little work have been done on group forecasts. 
This paper focuses on the judgemental forecasts given by consensus-seeking groups, which are routinely encountered in organisational contexts [17]. In light of previous work suggesting the importance of role-playing $[18,19]$ and the potential advantages of group processes in enhancing individual judgements [20-23], current study aims to compare the effects of role-playing on performance of group predictions and the associated forecast adjustment behaviour. Accordingly, the literature review and the research questions are presented in Section 2, while the details of the experimental study are given in Section 3. Section 4 provides the results, which are then discussed in Section 5 and followed by the conclusions in Section 6 .

\section{Literature review and research questions}

It is generally agreed that groups now form a significant element of organisations at all levels, which makes the identification of factors that influence group performance far more important than ever [24]. The extent of the currently available research on group decision making processes particularly in forecasting situations does not, however, match the rise in the pervasive use of groups in organisations. While groups make most of the vital forecasting decisions, studies focusing on individuals still constitute the majority of research in this area [12,25]. Surprisingly little work has been done with group forecasts. Notable exceptions are provided by (i) Ang and O'Connor [26] showing effects of group structuring on interval forecasting performance using peer groups, (ii) Sniezek [21] demonstrating that the relationship between group and individual predictive accuracy varies with the selected group technique, and (iii) Önkal et al. [20] reporting the performance differences in 'staticised' (i.e., averaged over individual forecasts given by group members) vs. group forecasts for different initial forecast conditions. There is certainly a need for more research on group forecasting in order to identify the influences of a wide variety of factors on group decision making processes. One such method to use for such an investigation is role-playing.

Role-playing has been used as a judgemental forecasting method particularly in conflict situations since the 1960s, producing highly valid results (for a review, see Ref. [18]). As early as in 1961, Cyert et al. [27, cf. 28] found that dissimilar forecasts from the same sets of numbers were produced by role players, depending on whether they played the role of the cost analyst or the sales analyst. Statman and Tyebjee [29] (1985) replicated the study and obtained similar results. Role-playing in this context is defined as ".... a technique whereby people play roles and enact a situation in a realistic manner... can be used to predict what will happen if various strategies are employed" [30, p. 807].

Empirical research on the value of role-playing suggests that role-play predictions result in considerably higher forecasting accuracy than unaided judgements [18,28,31]. Babcock et al. [32] provided evidence for the tendency of role players to make biased judgements and interpret the briefing material differently according to the role they were assigned, i.e. either defendant's or complainant's lawyers. In a recent study, Green and Armstrong [31] found that novice participants adopting roles of protagonists in conflict situations predicted the actual outcomes with 60\% accuracy. They concluded that it is highly useful to have groups of role players making decisions in simulated situations.

Most of the studies above that employed the role playing method for forecasting (e.g. [28,31]) have two features in common. Firstly, they use conflict situations for role-playing where the outcome is asked to be predicted by the role players. Predicting the outcome of a dispute can be considered as being substantially different from the more commonly encountered (and sometimes routine) forecasting decisions made in organisations, such as sales forecasts. Secondly, except in Green and Armstrong's [31] 'simulated interaction groups' study, role players represent the two parties in conflict over a dispute. ${ }^{1}$ As such, while the setting initially seems like a group decision making situation, role players make their predictions individually, after interacting with each other based on their roles. In real life situations, employees have to work in groups (not as opponents in a dispute) towards making a shared forecast decision, on which everyone is expected to agree. Therefore, it may be argued that these studies do not fully reflect the more commonly experienced forecasting decision-making situations in organisations and accordingly, there is need for such research, where role-playing is used for group-based forecasting decisions.

Another significant issue in group decision making is the influence of group dynamics that result in qualitative discrepancies in individual's behaviour (e.g. [33]). For instance, Song [34] argues that individuals tend to behave differently while making individual decisions vs. when working in groups. Another factor that influences the decision a group makes is the specific group decision-making mechanism. Evidence has been provided (e.g. $[35,36])$ that it is more difficult to reach a group decision using unanimity than majority rule. The unanimity rule encourages more careful examination of the decision at hand, hence means a more time-consuming process that delays the decision to be made.

In a similar vein, Bonner et al. [37] argue that ambiguity (i.e., lack of frames of reference), and recognition and use of expertise of group members are among the significant intra-group factors that influence group estimation processes. Decision making groups in organisational settings are usually comprised of members from different functional areas, who possess diverse types of information [38]. Moreover, groups usually portray a diverse picture in terms of their members' personalities, demographics, as well as expertise [39]. Individual competencies, skills, and knowledge of these members, collectively referred as expertise, are among salient resources available to the group. It has been demonstrated that the type of information decision makers have has a major effect on the final decision made by groups [40,41] How the group utilises its available resources therefore results in disparate performance, with information distortion having overarching effects on the use and diffusion of forecasts [42]. Bonner et al. [39] argue that how groups organise the use of these individual inputs to achieve their task, i.e. group coordination mechanisms, is linked to group performance. Similarly, CannonBowers et al. [43] claim that knowledge about group members' roles or expertise, i.e. 'mental models' of the team, have an effect on group behaviour and performance. Evidence for the positive impact of shared mental models on team coordination has also been provided [44,45], while Mathieu et al. [46] and Peterson et al. [47] found the same impact on team performance.

Research findings reported above have all been attained by using assessment or knowledge tasks and thus may have limited relevance for forecasting situations. In fact, researchers have argued that there exist fundamental differences between these two task types $[48,49]$. Although no direct references to group settings have been made, analyses of individual performance in general knowledge tasks vs. forecasting tasks have suggested that transference of results from one task domain to another remains quite dubious. Hence, performance in group settings with forecasting tasks require detailed investigation.

\footnotetext{
${ }^{1}$ In some rare situations, there was a role of an arbitrator
} 
Given the scarcity of research on group forecasts in spite of their frequent use and importance in organisational contexts, this paper aims to provide a fundamental step in exploring the performance of group predictions. Focusing on sales predictions given in structured groups, we aim to investigate the potential effects of role-playing on group forecasts and forecast adjustments. In so doing, our experimental framework utilises a case study organisation and requests groups to make sales forecasts for its different products. Participants are divided into role-playing vs. no-role-playing groups and are asked to engage in group discussions to arrive at consensus forecasts, thus replicating the typical forecasting meetings. For the roleplaying groups, special care is taken to provide very clear and unambiguous role instructions to participants, requesting that they put themselves into the position of the relevant manager in question and act/discuss accordingly. Detailed role inductions with examples are provided in separate sessions for different roles, as this is crucial for the validity of role-playing condition.

Additionally, all groups are provided with initial forecasts generated via an appropriate statistical forecasting technique. Such model-based forecasts are common in organisational forecasting settings, and they are typically regarded as forecast advice to be supplemented by individual judgement based on non-model information (e.g., pricing strategies, logistical problems, new store openings, competitor's promotions, etc.). The initial forecasts given to participants may also be viewed as providing 'meaningful informational cues' and thus may also be labelled as 'frames of reference' [37]. One of our research goals is to explore how frequently and how far the group's final consensus forecasts deviate from these initial forecasts. Such forecast adjustment behaviour has important repercussions for FSS-design issues like effects of forecast source [50] and nested adjustment behaviour [51], thus complementing the performance considerations in supply chain forecasts.

\section{Experimental method}

\subsection{Participants and design}

Thirty-nine MBA students at Bilkent University, who were taking a Probability and Statistics course, participated in the study. Students seemed extremely motivated and made a point of stating how much they enjoyed the group forecasting task at the end of the study. Use of student subjects is commonly encountered in previous work on group decision-making [52,53] and forecasting (see Ref. [12] for a review), with MBA students representing an advantageous participant pool given their job experiences (mean job experience $=2.9$ years for our participants).

Current study required consensus forecasts of sales for 20 different products of a hypothetical case study organisation (previously used in Ref. [20]) via a paper and pencil task. The experiment consisted of two parts, with background information presented in Part 1 and the forecast assessments made in Part 2. Specifically, Part 1 involved giving background information about the hypothetical organisation and describing the task requirements by specific examples. Participants were randomly allocated to three-person groups (making a total of $39 / 3=13$ groups). While six of the 13 groups were randomly assigned to groups where no role playing was involved, the remaining seven groups were labelled as role-playing groups. The no-role-playing (NRP) groups and the role-playing (RP) groups were taken into different classrooms, where separate sessions took place, as described in detail below.

\subsubsection{No role-playing groups}

Participants in groups where no role-playing was involved were taken into their break out rooms and they first started by drawing out unmarked envelopes to randomly pick their member identifier labels (labelled as $Q, X, W$-which were mere identifiers for the participants in groups and where the member receiving the ' $Q$ ' label acted to present the model forecast to the group). These participants were given time series plots and model forecasts for 20 different products of the case study organisation (a sample form is given in Appendix A). Their task was to engage in group discussions to come up with consensus forecasts for each product's sales for the next period. The group rules prohibited any member acting as a group leader and asked the participants to: (i) act with due consideration for all group members; (ii) let the member given the $\mathrm{Q}$ identifier introduce the initial forecast; (iii) record their levels of satisfaction with each of the consensus forecasts; (iv) record their preferred forecast (which would be equal to the consensus forecast only if they fully agreed with the group consensus); and ( $v$ ) evaluate each of the group members along with a self-evaluation upon task completion.

\subsubsection{Role-playing groups}

Group members assigned to RP groups first started by drawing out unmarked envelopes to randomly pick their roles as the Forecasting Executive, Marketing Director, or Production Director. This was followed by separate preparation sessions for each role conducted in different rooms to explain the specific role requirements-i.e., all participants with the same role received role inductions in one of three rooms (see Appendix B for the role information given to participants in Forecasting Executive, Marketing Director, and Production Director roles). At the end of the role-preparation sessions, the participants went to their designated group rooms for the group forecasting part of the study. At this stage, groups were asked to arrive at consensus forecasts for each product's one-period-ahead sales via group discussions. For each of the 20 products, they were given the time series, model forecasts for the next period, and their individual role scripts. That is, while all the subjects were presented with the same set of time-series, each participant received one of three stories to match their particular role (see Appendices C-E for the three role scripts given for the same product). The set of rules given to each group prohibited any member acting as a group leader while asking the participants to: (i) act out their given roles as they believed it would be performed in an organisation; (ii) act with due consideration for all group members; (iii) let the forecasting executive introduce the initial forecast; (iv) record their levels of satisfaction with each of the consensus forecasts; (v) record their preferred forecast (which would be equal to the consensus forecast only if they fully agreed with the group consensus); and (vi) evaluate each of the group members along with a self-evaluation upon task completion.

\subsubsection{Time series and initial forecasts}

Twenty artificially generated non-seasonal time series from Önkal et al. [20] were used in the study. The series were split into two sets of 10 with high variance and 10 with low variance (where high variance was equal to three times the low variance). For each of these sets, half were constructed from an AR(1) model and the other half from a model with simple linear trend plus a random normal deviate. These models were specifically selected to make the time series data representative of the actual sales patterns that could typically be encountered. To this end, each series also included one promotion in the given time series and six of the 20 series showed a promotion in the period to be forecasted. The promotion impact was generated by a stochastic function which increased the demand in the promotion period by $25-50 \%$ and decreased it in the following period by $15-40 \%$. Each time series plot showed 11 past observations, and asked for a 
forecast for the next period. Holt's Linear Exponential Smoothing technique was used to compute the initial model-based forecasts given to participants. When there was an upcoming promotion indicated for a product/series, a separate promotion effect forecast (calculated using the percentage effect on sales from the previous promotion for that product/series) was given to the participants in addition to the model forecast. In order to compute forecasting performance measures from the groups' predictions, we also generated Period 12's value for each time series.

\section{Results}

Performance measures used in this study address predictive accuracy of consensus forecasts as well as various facets of forecast adjustment from the initial model-based predictions. In particular, group forecasting accuracy is examined using the mean absolute percentage error (MAPE) while tendencies in forecast adjustment are investigated by breakdowns in directions of change (i.e., upward, downward, no change from model-based forecasts) as well as the magnitudes of change in group forecasts (i.e., mean percentage change (MPC) and mean absolute percentage change (MAPC) from the initially provided forecasts). Finally, we also examine comparative performance of composite forecasts (computed over the individual forecasts that are made subsequent to the group discussion and assessment of consensus forecasts) as benchmarks signalling the strength of consensus in groups.

\subsection{Forecast accuracy}

MAPE is a commonly used measure of forecasting accuracy, and is defined as the mean of the absolute percentage errors (APE) over a set of forecasts where,

Table 1

Mean score comparisons for the consensus forecasts given by groups in the roleplaying (RP) vs. no-role-playing (NRP) conditions.

\begin{tabular}{llll}
\hline & RP $(\%)$ & NRP $(\%)$ & RP vs. NRP \\
\hline MAPE & 10.35 & 11.73 & $t_{6}=-1.39 ; p=.215$ \\
\% adjusted upwards & 38.57 & 32.50 & $t_{9}=.81 ; p=.440$ \\
\% adjusted downwards & 28.57 & 59.17 & $t_{8}=-5.16 ; p=.001$ \\
\% unadjusted & 32.86 & 8.33 & $t_{10}=3.19 ; p=.010$ \\
MPC & 1.08 & -4.40 & $t_{9}=5.15 ; p=.001$ \\
MAPC & 4.29 & 8.76 & $t_{8}=-6.93 ; p<.001$ \\
\hline
\end{tabular}

$\mathrm{APE}=\{[\mid$ forecast - realized value $\mid] /$ realized value $\} \times 100$.

MAPE values for the role-playing and no-role-playing groups are given in Table 1 . Although the mean performance of roleplaying groups seems to be superior to that of the no-role-playing groups, these differences do not appear to be statistically significant $\left(t_{6}=-1.39\right.$, two-tailed $\left.p=.215\right)$. Given the small number of groups involved, the statistical power of these tests remain relatively low, and this is a common problem with group research overall $[20,21]$. Fig. 1 shows the individual MAPEs attained for each of the groups in the two conditions (RP and NRP). As can be gleaned from this Figure, role-playing groups show a considerably lower variability indicating consistently better accuracy (i.e., consistently low MAPE values), while the no-role-playing groups performances remain relatively volatile with higher MAPE figures indicating poorer accuracy.

\subsection{Forecast adjustment}

Forecast adjustments made by the groups in the two conditions are first analysed with respect to the breakdown of percentage of upward adjustments, downward adjustments, and no adjustments made to the initial forecasts. As can be seen from Table 1, there exists a significant pattern of differences between the two conditions. In particular, groups in role-playing condition leave a higher percentage of the forecasts unadjusted $\left(t_{10}=3.19\right.$; two-tailed $p=.010$ ). That is, when there are no particular role assignments and scripts, this seems to lead to a significantly higher proportion of adjustments made to the initially provided model-based forecasts. Furthermore, even though the groups in two conditions do not differ markedly in their percentage of upward adjustments, the no-role-playing groups appear to make higher percentage of downward adjustments $\left(t_{8}=-5.16\right.$; two-tailed $p=.001)$. Differences in the adjustment directions can be clearly seen in Fig. 2 .

We also examined the overall magnitude and direction of the forecast adjustments using the percentage change (PC) from initially provided predictions (i.e., model-based forecasts). That is:

$\mathrm{PC}=\{$ [group forecast - initial forecast $] /$ initial forecast $\} \times 100$.

The mean of percentage changes (MPC) over a set of group forecasts gives useful information about the overall positive/negative adjustment from the initially provided forecasts. As can be seen from Table 1, there exists a significant difference between the two conditions $\left(t_{9}=5.15 ; p=.001\right)$, with the role-playing groups giving a lower and positive adjustment as compared to the no-role-playing

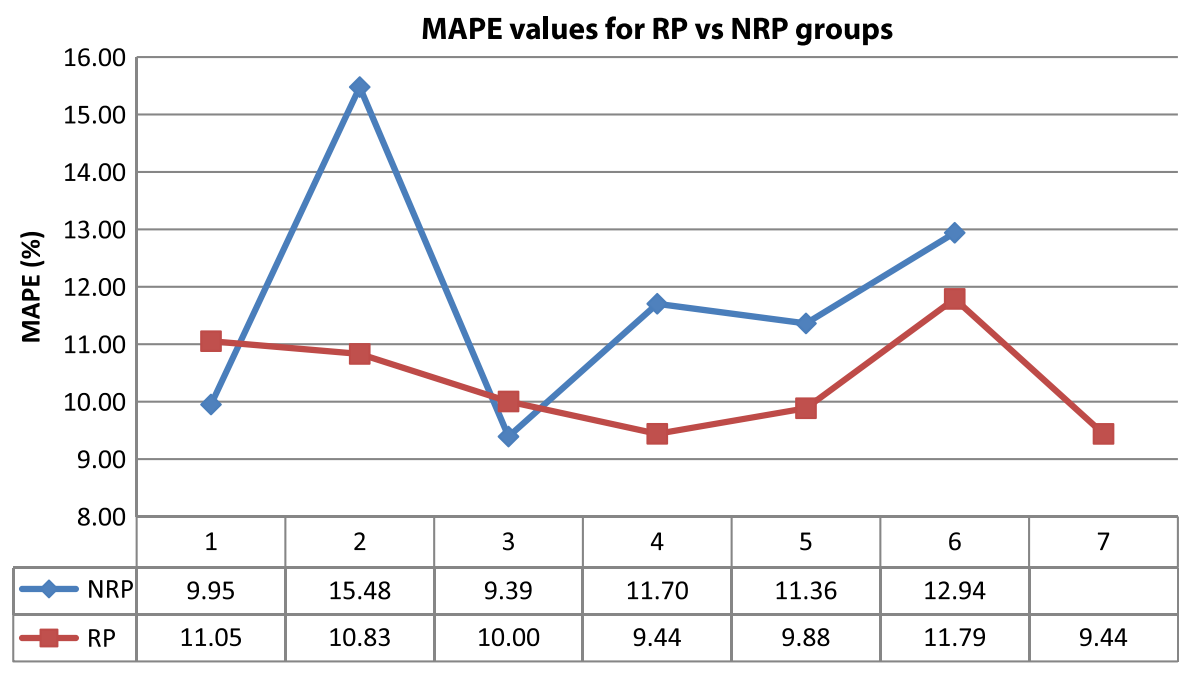

Fig. 1. MAPE scores for the separate groups in the Role-Playing-Group Condition vs. the No-Role-Playing Group Condition. 
RP: ADJUSTMENT PATTERN

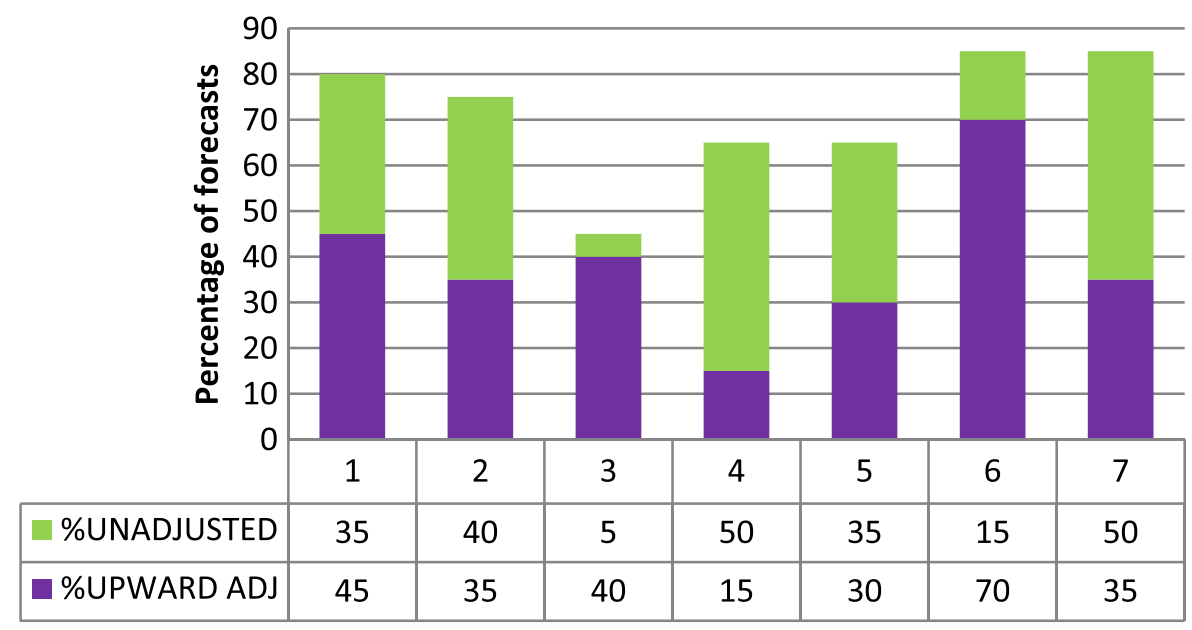

NRP:ADJUSTMENT PATTERN

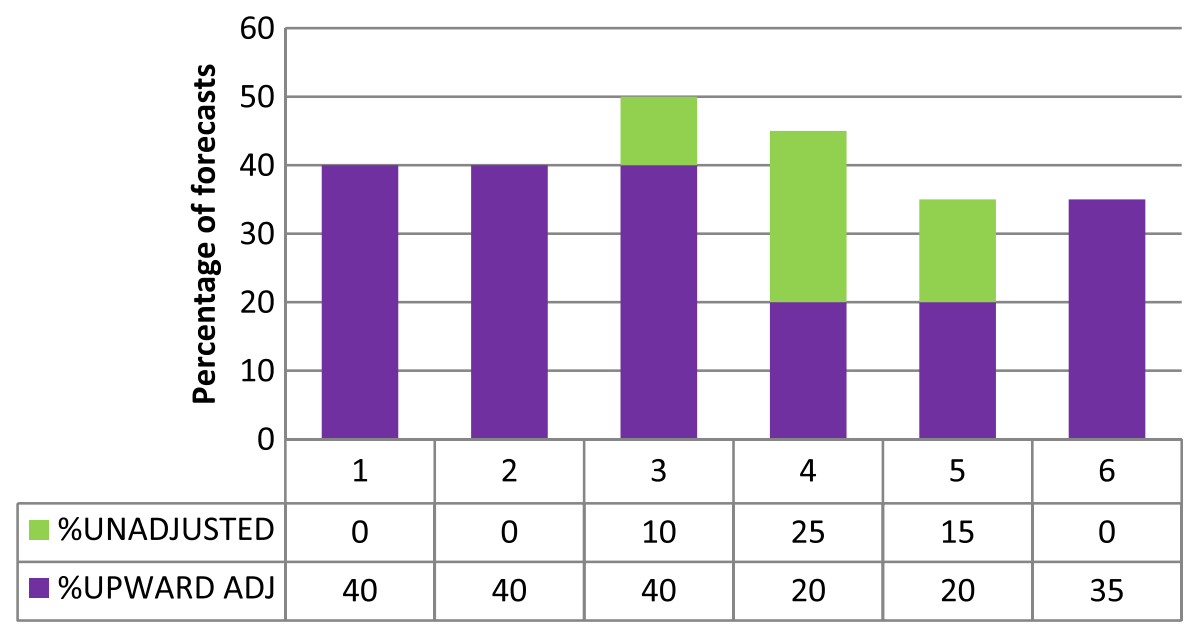

Fig. 2. Adjustment direction patterns of the Role-Playing-Groups vs. the No-Role-Playing Groups.

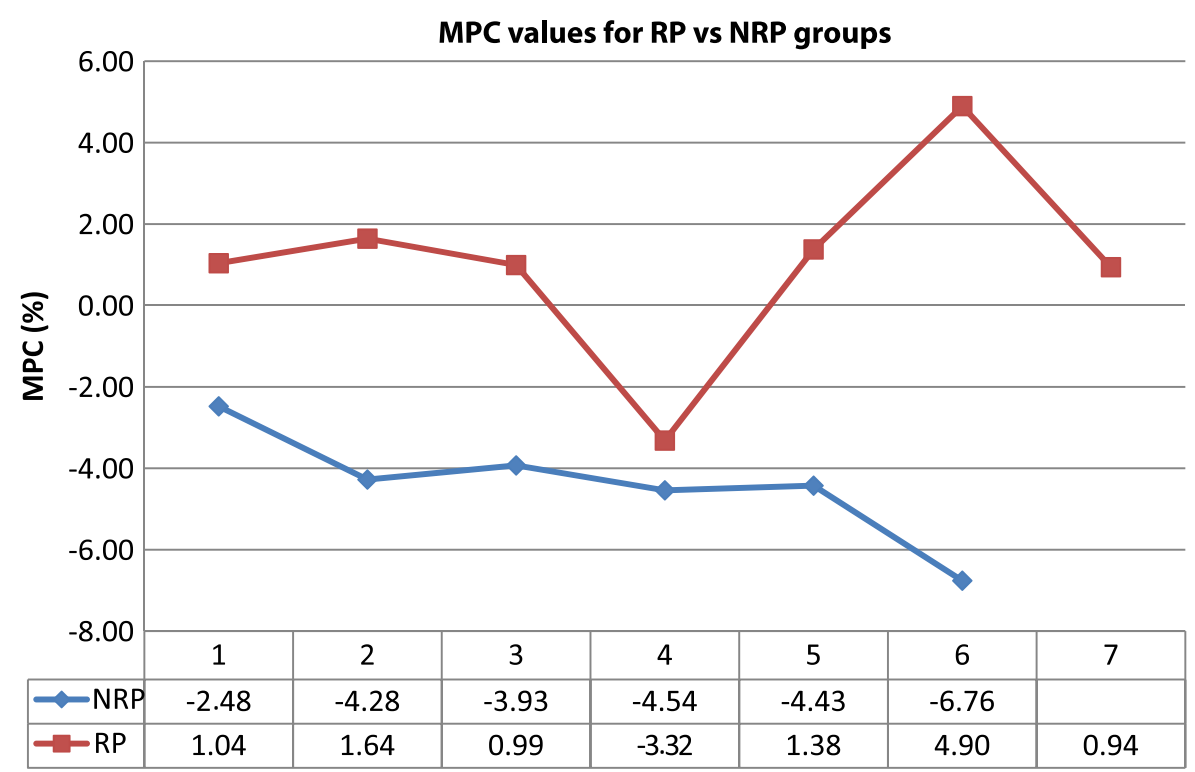

Fig. 3. MPC scores for the separate groups in the Role-Playing-Group Condition vs. the No-Role-Playing Group Condition.

groups that give a higher and negative adjustment. These differences become more apparent when group breakdowns are examined in Fig. 3.
Relatedly, Mean Absolute Percentage Change (MAPC) scores were computed to explore whether role-playing has any effects on the consensus forecasts' proximity (in absolute distance terms) 


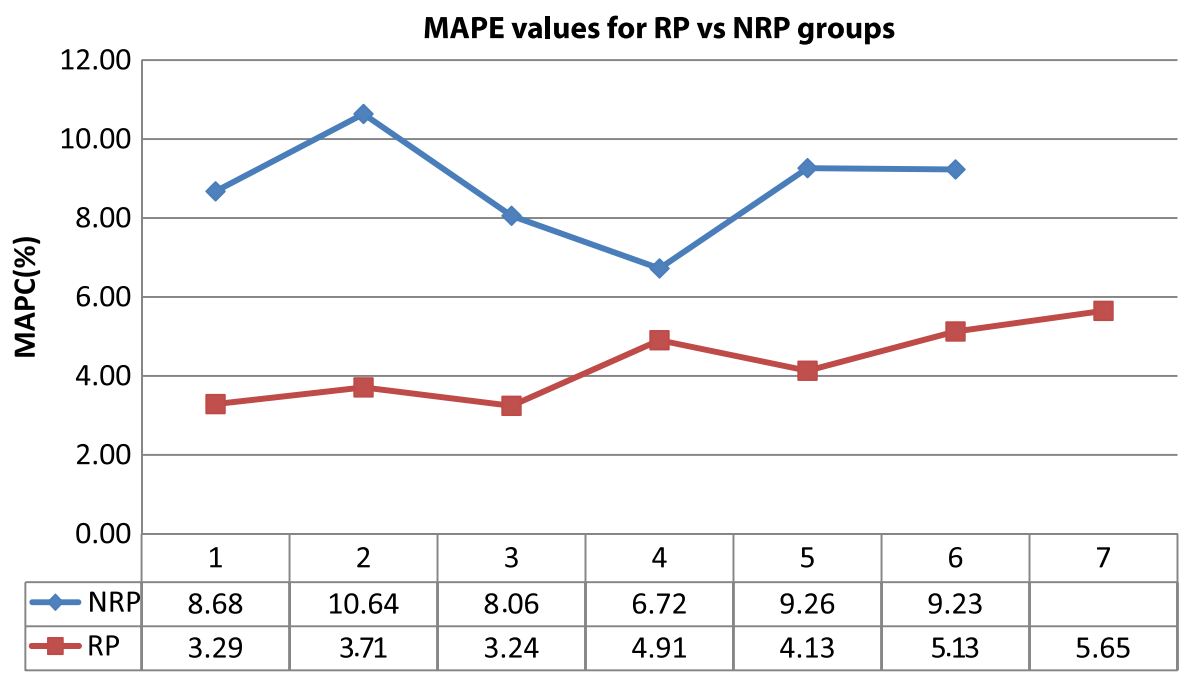

Fig. 4. MAPC scores for the separate groups in the Role-Playing-Group Condition vs. the No-Role-Playing Group Condition.

Table 2

Mean scores of composite group forecasts in the role-playing (RP) vs. no-role-playing (NRP) conditions.

\begin{tabular}{|c|c|c|c|}
\hline & $\mathbf{R P}(\%)$ & NRP (\%) & RP vs. NRP \\
\hline Composite forecasts: MAPE & 10.73 & 11.74 & $t_{7}=-.99 ; p=.357$ \\
\hline Composite forecasts: deviation from consensus & 1.79 & .40 & $t_{6}=1.69 ; p=.143$ \\
\hline
\end{tabular}

to the provided initial forecasts (i.e., frames of reference). Table 1 shows that while the no-role-playing groups' final forecasts reflect an average of approximately $9 \%$ adjustment of the initial model forecasts, role-playing groups only make an average of $4 \%$ adjustment over the given predictions. This significant difference in adjustment behaviour $\left(t_{8}=-6.93\right.$; two-tailed $\left.p<.001\right)$ indicates that providing structured roles and scripts to group members leads to less adjustments (lower MAPC). Fig. 4 provides the group breakdowns showing the consistently smaller deviations from the initial forecasts (MAPC values) given by the groups in the role-playing condition.

\subsection{Consensus forecasts vs. composite forecasts}

Following group discussion and assessment of a single consensus forecast for each product's sales for the next period (i.e., for each of the 20 time series), individual group members were also asked to give their own preferred forecast (which would be equal to the consensus figure only if they totally agreed with the consensus forecast given by the group). The individual forecasts were then averaged over the three group members to attain the composite forecast for the group. As displayed in Table 2, no significant differences could be found between the role-playing and no-role-playing groups in the accuracy of these 'composite' predictions. Furthermore, comparisons of these composite predictions to the consensus forecasts show no significant differences in accuracy (i.e., MAPE) for groups in either condition $\left(t_{10}=.66 ; p=.527\right.$ for RP; $t_{9}=-.05 ; p=.964$ for NRP).

Additionally, role playing does not seem to make a difference in the average percentage deviation of composite forecasts from the consensus forecasts. However, if we were to examine the percentage of occasions when all three members' individual forecasts (following group discussion) were exactly equal to the consensus forecast, we find that while three of the six no-roleplaying groups totally embrace the consensus forecast as their individually preferred forecasts (yielding an average of $78 \%$ of the products where all the individual forecasts in the group are identical to the group consensus forecast), individual differences are much higher in the role-playing group (with an average adoption of consensus forecast for $44 \%$ of the products).

\section{Discussion}

This study was aimed at investigating the salience of role playing on the accuracy of sales forecasts in group-based forecasting settings. For this purpose, we provided role scripts to half of the participants, in terms of detailed role definitions for marketing and production managers as well as for forecasting executives. Relevant scripts for each of the time series plots (representing sales of different products) were also written according to the specific role definitions. Participants in the no-role-playing groups did not receive these scripts. Interestingly, no significant differences could be found between the accuracy levels of consensus forecasts given by groups in the role-playing vs. no-role-playing conditions. Since we are not aware of any previous work using group forecasts and role-playing, we do not have a basis for comparing these findings to past results. That is, extant literature in this field comprises of studies that compare individual unaided forecasts with role-playing ones (e.g. [28,31]) or individual forecasts with (or without) frames of reference compared to group forecasts (also with or without such cues; e.g. $[24,37,39])$. Although the consensus forecasts given by roleplaying groups yielded consistently lower errors, while those given by no-role-playing groups showed a wide variability in accuracy, statistical significance could not be shown. Small 
sample size issues (resulting in low statistical power of tests) commonly observed in studies with groups could provide a potential explanation; forecasting error patterns of individual groups do provide support for this. Future work with larger number of groups should prove informative in this regard.

A further explanation may be provided by group-specific factors inherent in group decision making processes, which we did not assess in this study. Bonner et al. [37] for instance considered expertise, perceived expertise, centrality, and extroversion as potentially influential factors for decision-making patterns of groups. Their findings revealed that “... people can be influential in a group through their personality or through their expertise and that the nature of the task dictates the more telling characteristic" [37, p. 130]. They also found that groups can be very good at integrating members' expert knowledge into their forecasts but only when there are external frames of reference available. When no such cues are provided, group estimates are influenced heavily by extrovert members, irrespective of their expertise. There might have been specific group dynamics issues (e.g., dominating member, conflicts among members, presumed expertise effects, etc.) in effect in the experimental setting we used, so that role-playing could of have been perceived as much less salient, leading groups in both conditions to give similarly performing forecasts. Using differently structured group settings will prove immensely valuable in testing (and possibly extending) the group factors proposed in Bonner et al.'s [37] model.

While no significant differences could be found between the forecasting accuracy levels of RP and NRP groups, we were able to find evidence for a significant difference between the strength of consensus levels for RP and NRP groups. In particular, relative to NRP groups, RP groups appeared more committed to their own roles and scripts, showing less agreement with the consensus forecasts. This finding can be interpreted as providing support for the salience of organisational roles on the forecasting decisions, where individuals might make divergent decisions/forecasts in group settings in accordance with their different roles. This could further be viewed as an important role-defence strategy that may potentially lead to significant biases-i.e., individuals may be strategically distorting their forecasts to mainly defend and justify their assumed roles. Accordingly, strategic consequences of assumed roles and framing differences need to be systematically investigated. The results will undoubtedly improve the elicitation and use of organisational forecasts via effective tailoring of feedback and training mechanisms.

Other differences between the groups were revealed in performance scores for forecast adjustments performed on the initially provided model predictions. In particular, role-playing groups appeared to leave a higher percentage of the model-based forecasts unadjusted (33\% of the initial forecasts unadjusted for RP vs. 8\% unadjusted for NRP). That is, not having any particular role assignments and scripts appeared to lead to a significantly higher proportion of adjustments made to the initially provided model-based forecasts (92\% of initial forecasts adjusted in NRP groups vs. 67\% adjusted in RP groups). Furthermore, the no-roleplaying groups seemed to make higher percentage of downward adjustments, while the groups in two conditions made similar percentages of upward adjustments to the initial forecasts. Additionally, the role-playing groups gave lower and positive overall adjustments (as compared to the no-role-playing groups that gave a higher and negative overall adjustment). Relatedly, while the no-role-playing groups' final forecasts reflected an average of approximately 9\% adjustment of the initial model forecasts, role-playing groups only made an average of $4 \%$ adjustment over the given predictions in absolute terms. This significant difference in adjustment behaviour $\left(t_{8}=-6.93\right.$; two- tailed $p<.001$ ) indicates that providing structured roles and scripts to group members leads to less adjustments (lower MAPC). Fig. 4 provides the group breakdowns showing the consistently smaller deviations from the initial forecasts (MAPC values) given by the groups in the role-playing condition. In short, groups in the role-playing condition appeared to make less overall adjustments from the given model predictions, again highlighting the potential importance of role framing on adjustment behaviour. This issue definitely deserves further research attention as the acceptance of given forecast advice (as signalled through the consistency, magnitude and direction of changes made to model-based forecasts) provides a real challenge in the design of decision and forecast support systems [54,55] with critical repercussions for knowledge management and information dissemination in organisations.

\section{Conclusion}

This paper presents an exploratory step in examining the wisdom of group forecasts. Given their prevalence in organisations, group forecasts provide important platforms to explore multi-faceted issues relating to group dynamics, knowledge management, information sharing, use of forecast advice, and collaborative forecasting. Further research into these venues is essential to improve the accuracy and acceptance of organisational forecasts, leading to more effective processes for decision making and business planning.

\section{Appendix A. Sample time series given to participants in the no-role condition}

Fig. A1

Last promotion period: 9

MODEL FORECAST for period 12: 270

YOUR FORECAST for period 12:

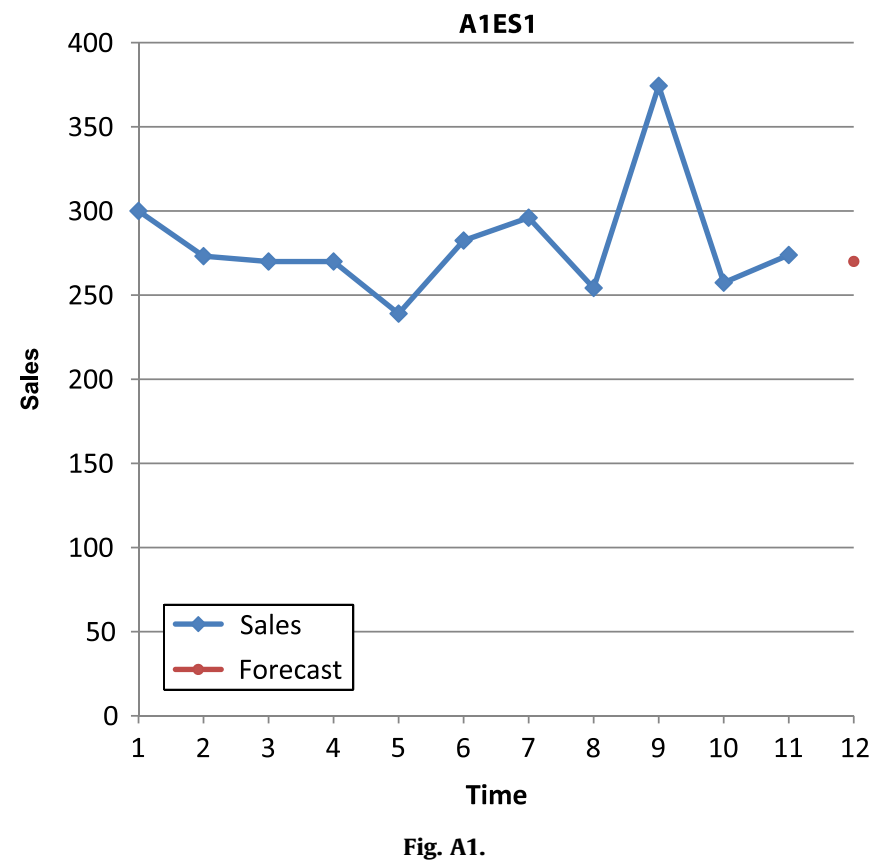


Appendix B. Role information for the 'forecasting executive', 'marketing director', and 'production director' roles

Forecasting Executive (chief information officer-CIO)

The Forecasting Executive is one of those executives, who report directly to the CEO. The major responsibility of this position is the development of the most accurate forecasts for the company. You, as the Forecasting Executive, believe that the profitability of the company is mainly dependent on the success of its forecasts, as production is based on them, which can in turn reduce or increase inventory and manufacturing costs. Therefore, you feel that your position is superior than the other positions reporting to the CEO. You personally believe that since your appointment as the $\mathrm{CIO}$, Delta Gizmo has been successful primarily due to the excellent job you have done in the forecasting department.

Considerable investment has been made in the last few years to upgrade the computer information systems of Delta Gizmo. The upgraded systems include a state of the art computerised forecasting system, which has been demonstrated to be as accurate as possible given the randomness of the data. In addition, the computer forecasts so far appear more accurate than the forecasts previously prepared by the Sales and Marketing Departments. Each month you, as the Forecasting Executive, make sure that the job of massaging the data base (with the help of the forecasting software) is being properly done to remove the impacts of special events like promotions. This is needed for the base line forecast to be as accurate as possible. You review each forecast carefully before the Forecast Committee meeting. At each monthly Forecasting Meeting, you collaborate with the Marketing and Production Directors to achieve the best company forecasts by working on the computer forecasts and any additional data brought forward by these directors. However you, as the executive in charge of preparing the computerised forecasts, feel quite strongly that changes to these should only be made when a promotion is coming up or someone in the meeting can see a problem with the computer forecast. Since the CEO has taken steps to increase the power of the Forecasting Executive's position in the Forecast Committee, you feel much more comfortable in asserting the accuracy of the computer forecasts. Your one concern, however, is that you have not been formally trained in forecasting, nor has anyone else in your unit. Therefore, you feel vulnerable when you are challenged on the need to change forecasts due to observed patterns in the time series that seem not to be reflected in the computer forecast. This does happen from time to time, as even the best forecast can be wrong and needs to be modified.

\section{Marketing Director}

The Marketing Director is one of the executives, who report directly to the CEO. The major responsibility of this position is to run the marketing operations of Delta Gizmo successfully. You, as the Marketing Director, believe that the profitability of the company is mainly dependent on the success of its marketing operation. Therefore, you feel that your position is superior than the other positions reporting to the CEO. You personally believe that, since your appointment as the Marketing Director, the success of Delta Gizmo is primarily due to the excellent job you have done in marketing the products, leading to strongly increasing sales through the years.

The best way to increase sales, you believe, is to run successful promotions regularly for the key products to keep them highly visible in the public eye. You claim that "stretch forecasts", (i.e., forecasts adjusted upwards from the statistical predictions given by the computerised forecasting system) have to be made for two important reasons: (1) to ensure that stock is available in case a promotion becomes very successful and results in unexpectedly high sales, and (2) higher forecasts act as an incentive for the sales staff to do their very best. If the forecast is on the low side, you worry that the sales staff may well adopt a relaxed attitude rather than putting in more effort to reach their targets. There is a revised bonus system (strongly pushed by the CEO to stop the over-forecasting) that has been designed to counter this possibility, but you are not so sure of its effects. After all, "stretch forecasts" have worked well in the past and you do not think that the cost of extra stock is your problem. You are also eager to make sure that the final forecasts reflect the considerable Market Intelligence you bring to the Forecast Committee. You are concerned that the Forecasting Executive is too keen on the computer forecasts. Furthermore, you believe that his/her knowledge of forecasting is at times a bit doubtful. You are also worried that the Production Executive is becoming increasingly forceful in seeking to lower the forecasts. S/he does not mind taking it even to the point where, as happened in a few instances last year, the stock ran out completely, costing the company lost sales. You have been mentioning this regularly to keep him/her aware of the risks of dropping the forecasts.

\section{Production Director}

The Production Director is one of the executives, who report directly to the CEO. The major responsibility of this position is to run a successful operation of Delta Gizmo's manufacturing facility. You, as the Production Director, believe that the profitability of the company is mainly dependent on the success of its manufacturing operations in reducing the production costs. Therefore, you feel that your position is superior than the other positions reporting to the CEO. You personally believe that, since your appointment as the Production Director, the success of Delta Gizmo is primarily due to the excellent job you have done in the manufacturing facility resulting in strongly decreasing costs each year. Over the last few years, the unit costs have been driven down by persistent improvements in the manufacturing process as well as the intense involvement of all the manufacturing employees in the improvement programme.

You firmly feel that there is strong evidence supporting your belief that the reduction in the cost base has been the major reason for the strong sales growth. Thus you disapprove of the overly proud behaviour of the Marketing Director, who seeks to take all the credit for the sales growth for himself/herself. Furthermore, you are upset that so much money has been lost over the last few years in excessive inventory due to overly optimistic sales forecasts. This was, you believe, the result of Marketing Director's insistence on "stretch forecasts"-i.e., his pressures to adjust the forecasts upwards from the statistical predictions given by the computerised forecasting system. Hence, you are determined to do what you can to make sure that the forecasts are realistic. This may be difficult as the Marketing Director is a strong individual, and if they do run out of stock due to your actions, you know you will be held responsible. This happened a few times in the last year and they still remind you of these instances in the meetings.

\section{Appendix C. Sample time series given to participants in the 'forecasting executive' role}

Fig. C1

Last promotion period: 9

MODEL FORECAST for period 12: 270 


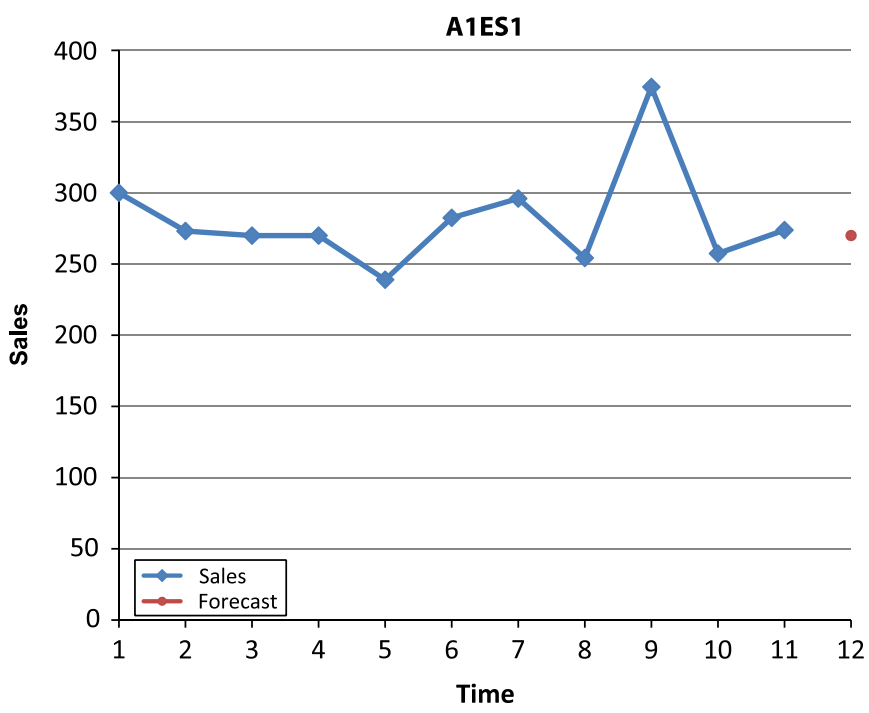

Fig. C1.

SCRIPT FOR YOUR ROLE AS THE FORECASTING EXECUTIVE:

"The baseline forecast reflects the long-term fairly stable trend in this product. It therefore seems realistic to us."

YOUR FORECAST for period 12:

\section{Appendix D. Sample time series given to participants in the 'marketing director' role}

Fig. D1

Last promotion period: 9

MODEL FORECAST for period 12: 270

SCRIPT FOR YOUR ROLE AS THE MARKETING DIRECTOR:

"We do not believe that the forecast reflects the slightly upward trend which looks more likely in the long term. We would be happier with the forecast set higher than the model prediction."

YOUR FORECAST for period 12:

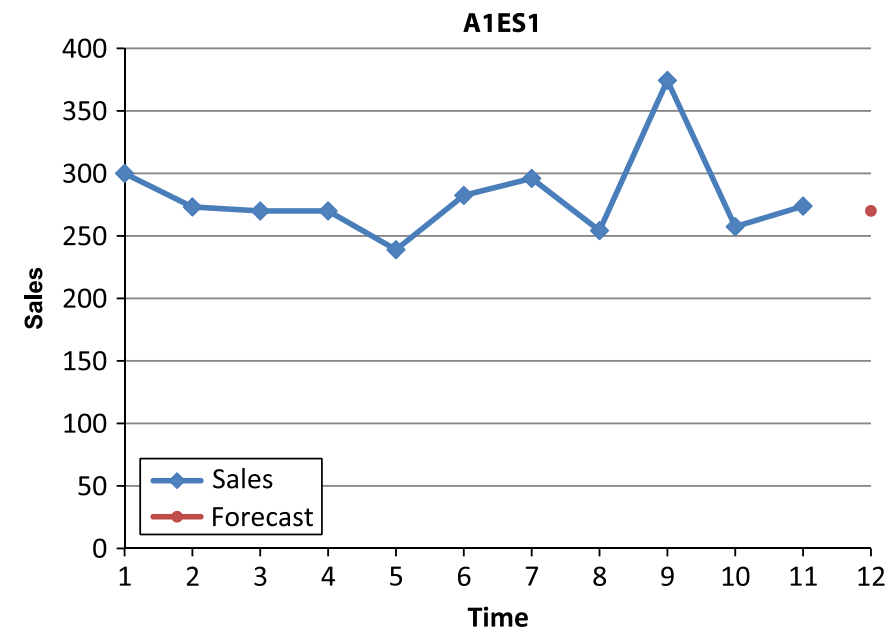

Fig. D1.
Appendix E. Sample time series given to participants in the 'production director' role

Fig. E1

SCRIPT FOR YOUR ROLE AS THE PRODUCTION DIRECTOR:

Last promotion period: 9

MODEL FORECAST for period 12: 270

"We believe that the forecast is on the optimistic side for this product. We would like to see a more realistic figure, which reflects the mostly downward trend observed in the last 11 periods. We would be happier with the forecast set lower than the model prediction".

YOUR FORECAST for period 12:

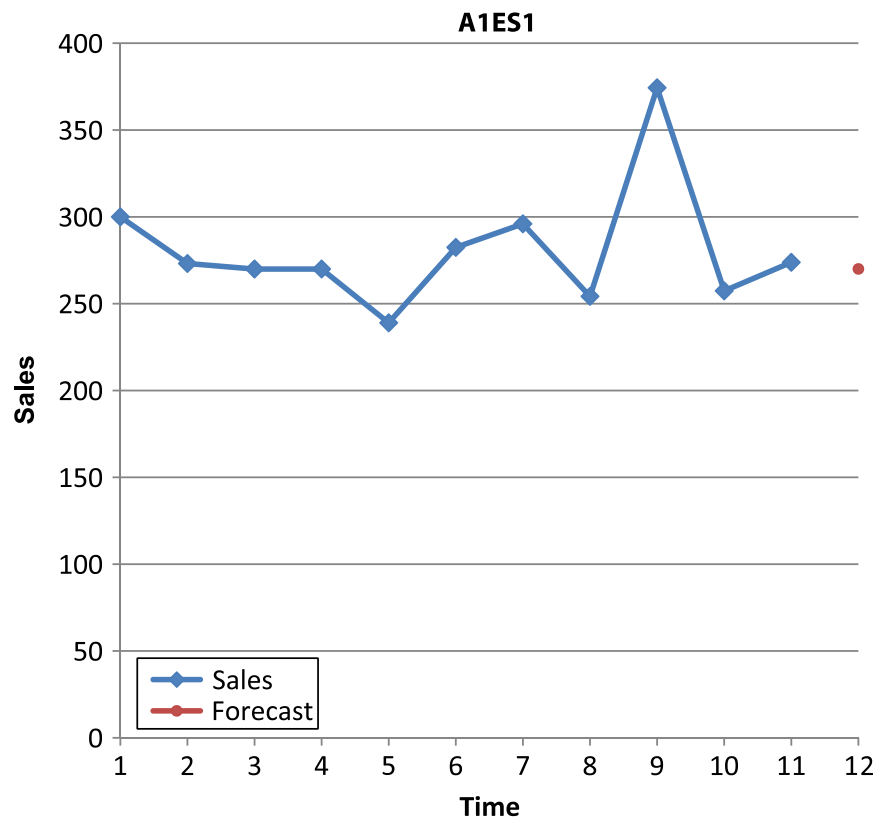

Fig. E1.

\section{References}

[1] Sanders NR. Accuracy of judgemental forecasts: a comparison. Omega: The International Journal of Management Science 1992;20:353.

[2] Boylan JE, Syntetos AA. Classification for forecasting and stock control: a case study. Journal of the Operational Research Society 2008;59:473-81.

[3] Syntetos AA, Boylan JE. The accuracy of intermittent demand estimates. International Journal of Forecasting 2005;21:303-14.

[4] Raghunathan S. Interorganisational collaborative forecasting and replenishment systems and supply chain implications. Decision Sciences 1999;30: 1053-71.

[5] Zhang X. The impact of forecasting methods on the bullwhip effect. International Journal of Production Economics 2004;88:15-27.

[6] Zhao XD, Xie JX, Leung J. The impact of forecasting model selection on the value of information sharing in a supply chain. European Journal of Operational Research 2002;142:321-44.

[7] Syntetos AA, Nikolopoulos K, Boylan JE, Fildes R, Goodwin P. The effects of integrating management judgement into intermittent demand forecasts. International Journal of Production Economics 2009;118:72-81.

[8] Gaur V, Kesavan S, Ramanand A, Fisher ML. Estimating demand uncertainty using judgemental forecasts. Manufacturing \& Service Operations Management 2007;9:480-91.

[9] Fildes R, Goodwin P, Lawrence M, Nikolopoulos K. Effective forecasting and judgemental adjustments: an empirical evaluation and strategies for improvement in supply-chain planning. International Journal of Forecasting 2009;25:3-23.

[10] Sanders NR. Comments on "Effective forecasting and judgemental adjustments: an empirical evaluation and strategies for improvement in supplychain planning". International Journal of Forecasting 2009;25:24-6.

[11] Fildes R, Goodwin P, Lawrence M. The design features of forecasting support systems and their effectiveness. Decision Support Systems 2006;42:351-61. 
[12] Lawrence M, Goodwin P, O’Connor M, Önkal D. Judgemental forecasting: a review of progress over the last 25 years. International Journal of Forecasting 2006;22:493-518.

[13] Önkal D, Gönül MS. Judgemental adjustment: a challenge for providers and users of forecasts. Foresight: The International Journal of Applied Forecasting 2005;1:13-7.

[14] Lawrence M, O'Connor M, Edmundson B. A field study of sales forecasting accuracy and processes. European Journal of Operational Research 2000;122: 151-60.

[15] Gönül MS, Önkal D, Goodwin P. Expectations, use and judgemental adjustment of external financial and economic forecasts: an empirical investigation. Journal of Forecasting 2009;28:19-37.

[16] Sanders NR, Graman GA. Quantifying costs of forecast errors: a case study of the warehouse environment. Omega: The International Journal of Management Science 2009;37:116-25

[17] González-Pachón J, Romero C. The design of socially optimal decisions in a consensus scenario. Omega: The International Journal of Management Science 2011;39:179-85.

[18] Armstrong JS. Role playing: a method to forecast decisions. In: Armstrong JS editor. Principles of Forecasting: A Handbook for Researchers and Practitioners. Norwell, MA: Kluwer Academic; 2001. p. 15-30.

[19] Armstrong JS. Assessing game theory, role playing, and unaided judgement. International Journal of Forecasting 2002;18:345-52.

[20] Önkal D, Lawrence M, Sayım KZ. Influence of differentiated roles on group forecasting accuracy. International Journal of Forecasting 2011;27:50-68.

[21] Sniezek J. An examination of group process in judgemental forecasting. International Journal of Forecasting 1989;5:171-8.

[22] Sniezek J, Henry RA. Accuracy and confidence in group judgement. Organisational Behaviour and Human Decision Processes 1989;43:1-28.

[23] Sniezek J, Henry RA. Revision, weighting, and commitment in consensus group judgement. Organizational Behaviour and Human Decision Processes 1990;45:66-84.

[24] Baumann MR, Bonner BL. The effects of variability and expectations on utilization of member expertise and group performance. Organizational Behaviour and Human Decision Processes 2004;93:89-101.

[25] Milch KF, Weber EU, Appelt KC, Handgraaf MJJ, Krantz DH. From individual preference construction to group decisions: framing effects and group processes. Organizational Behaviour and Human Decision Processes 2009;108:242-55.

[26] Ang S, O'Connor M. The effect of group interaction strategies on performance in time series extrapolation. International Journal of Forecasting 1991;7:141-9.

[27] Cyert RM, March JG, Starbuck WH. Two experiments on bias and conflict in organisational estimation. Management Science 1961;7:254-64.

[28] Green KC. Forecasting decisions in conflict situations: a comparison of game theory, role-playing, and unaided judgement. International Journal of Forecasting 2002;18:321-44.

[29] Statman M, Tyebjee TT. Optimistic capital budgeting forecasts: an experiment. Financial Management, Autumn 1985:27-33.

[30] Armstrong JS. The forecasting dictionary. In: Armstrong JS, editor. Principles of forecasting: A Handbook for Researchers and Practitioners. Norwell, MA: Kluwer Academic; 2001. p. 761-824

[31] Green KC, Armstrong JS. Role thinking: standing in other people's shoes to forecast decisions in conflicts. International Journal of Forecasting 2011;27:69-80.

[32] Babcock L, Loewenstein G, Issacharoff S, Camerer C. Biased judgements of fairness in bargaining. The American Economic Review 1995;85:1337-43.

[33] Insko CA, Pinkley RL, Hoyle RH, Dalton B, Hong G, Slim R. Individual-group discontinuity: the role of intergroup contact. Journal of Experimental Social Psychology 1987;23:250-67.

[34] Song F. Trust and reciprocity behaviour and behavioural forecasts: individuals versus group-representatives. Games and Human Behaviour 2008;62:675-96.
[35] Castore C, Murnighan JK. Determinants of individual support of group decisions. Organisational Behaviour and Human Performance 1978;22: 75-92.

[36] Miller CE. The social psychological effects of group decision rules. In: Paulus $\mathrm{BP}$, editor. Psychology of Group Influence. 2nd edition. Hillsdale, NJ: Lawrence Erlbaum Associates; 1989. p. 327-55.

[37] Bonner BL, Sillito SD, Baumann MR. Collective estimation: accuracy, expertise, and extroversion as sources of intra-group influence. Organizational Behaviour and Human Decision Processes 2007;103:121-33.

[38] Dennis AR. Information exchange and use in group decision-making: you can lead a group to information but you can't make it think. MIS Quarterly 1996;20:583-93.

[39] Bonner BL, Baumann MR, Dalal RS. The effects of member expertise on group decision-making and performance. Organizational Behaviour and Human Decision Processes 2002;88:719-36.

[40] Howard RA. Decision analysis: practice and promise. Management Science 1988:34:379-95.

[41] Stasser G. Information salience and the discovery of hidden profiles by decision-making groups: a "thought experiment". Organizational Behaviour and Human Decision Processes 1992;52:156-81.

[42] Balan S, Vrat P, Kumar P. Information distortion in a supply chain and its mitigation using soft computing approach. Omega: The International Journal of Management Science 2009;37:282-99.

[43] Cannon-Bowers JA, Salas E, Converse S. Shared mental models in expert team decision making. In: Castellan NJJ, editor. Individual and Group Decision Making: Current Issues. Hillsdale, NJ: Erlbaum; 1993. p. 221-46.

[44] Blickensderfer E, Cannon-Bowers JA, Salas E. The relationship between shared knowledge and team performance: a field study. Paper presented at the Annual Meeting of the American Psychological Society. Miami, FL; 2000.

[45] Mathieu JE, Goodwin GF, Heffner TS, Salas E, Cannon-Bowers JA. The influence of shared mental models on team processes and performance. Journal of Applied Psychology 2000;85:273-83.

[46] Mathieu JE, Heffner TS, Goodwin GF, Cannon-Bowers JA, Salas E. Scaling the quality of teammates' mental models: equifinality and normative comparisons. Journal of Organisational Behaviour 2005;26:37-56.

[47] Peterson E, Mitchell TR, Thompson L, Burr R. Collective efficacy and aspects of shared mental models as predictors of performance over time in work groups. Group Processes and Intergroup Relations 2000;3:296-316.

[48] Wright. G, Ayton P. Subjective confidence in forecasts: a response to Fischhoff and MacGregor. Journal of Forecasting 1986;5:117-23.

[49] Ronis DL, Yates JF. Components of probability judgement accuracy: individual consistency and effects of subject matter and assessment method. Organizational Behaviour and Human Decision Processes 1987;40:193-218.

[50] Önkal D, Goodwin P, Thomson M, Gönül MS, Pollock A. The relative influence of advice from human experts and statistical methods on forecast adjustments. Journal of Behavioural Decision Making 2009;22:390-409.

[51] Önkal D, Gönül MS, Lawrence M. Judgemental adjustments of previouslyadjusted forecasts. Decision Sciences 2008;39:213-38.

[52] Filios VP. Where should be the trends in current accounting research? Human Systems Management 1992;11:203-11.

53] Valacich JS, Sarker S, Pratt J, Groomer M. Understanding risk-taking behaviour of groups: a "decision analysis" perspective. Decision Support Systems 2009;46:902-12.

[54] Lawrence M, Goodwin P, Fildes R. Influence of user participation on DSS use and decision accuracy. Omega: International Journal of Management Science 2002;30:381-92.

[55] Goodwin P, Fildes R, Lawrence M, Stephens G. Restrictiveness and guidance in support systems. Omega: The International Journal of Management Science 2011;39:242-53. 